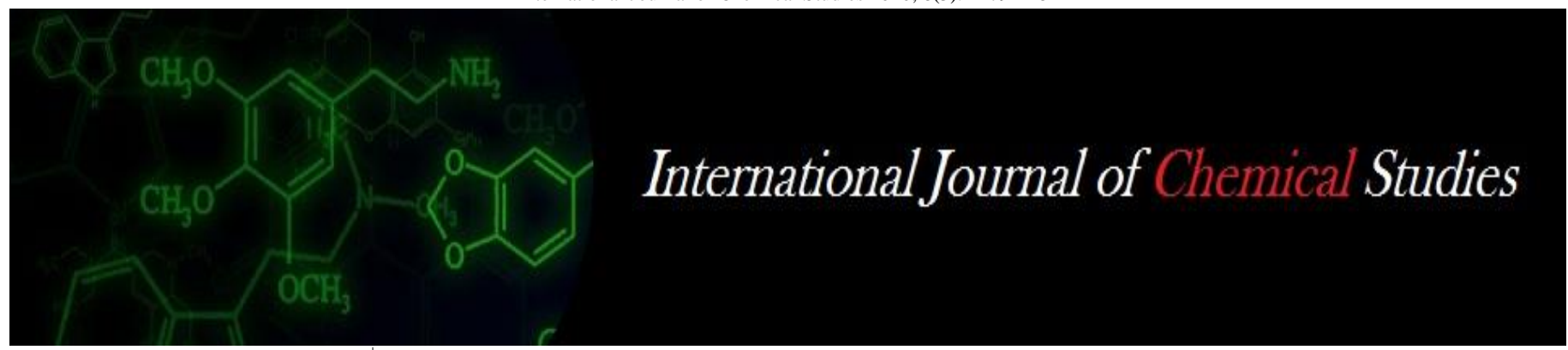

P-ISSN: 2349-8528

E-ISSN: 2321-4902

www.chemijournal.com

IJCS 2020; 8(3): 1479-1482

(C) 2020 IJCS

Received: 15-03-2020

Accepted: 16-04-2020

\section{SS Mehesare}

Ph.D. Student, Department of

Veterinary Clinical Medicine,

Ethics and Jurisprudence,

PGIVAS, Akola, Maharashtra, India

\section{SP Waghmare}

Professor and Head, Department of Veterinary Clinical Medicine, Ethics and Jurisprudence, PGIVAS, Akola, Maharashtra, India

\section{MG Thorat}

Professor and Head, Department of Veterinary Surgery and Radiology, PGIVAS, Akola, Maharashtra, India

\section{SW Hajare}

Assistant Professor and Head, Department of Pharmacology and Toxicology, PGIVAS,

Akola, Maharashtra, India

\section{PR Itanka}

Assistant Professor (Sr. Gr.), Department of Pharmaceutical Sciences, Rashtrasant Tukadoji Maharaj Nagpur University, Nagpur, Maharashtra, India

\section{Quantitative analysis of biomarkers in hydro- ethanolic extract of Aegle marmelos by High Performance Thin Layer Chromatography (HPTLC)}

\author{
SS Mehesare, SP Waghmare, MG Thorat, SW Hajare and PR Itankar
}

DOI: https://doi.org/10.22271/chemi.2020.v8.i3t.9403

\begin{abstract}
In the present study the quantitative phytochemical analysis of extract of unipe fruits of Aegle marmelos was carried out with specific biomarkers like gallic acid, quercetin and rutin by high-performance liquid chromatography (HPLC). The detection and quantification of these markers were performed at $200-450$ $\mathrm{nm}$ wavelength with reference to standards in mobile phase Toulene: Ethyl Acetate: Formic Acid: Methanol (3:3:0.3:0.2). The hydro-ethanolic extract of unripe fruits of Aegle marmelos showed peak $R f$ values which were coinciding with standard $R f$ value of gallic acid and quercetin. The $R f$ values for gallic acid and quercetin in sample and reference standard were found comparable. These observations indicated the presence of gallic acid and quercetin in hydro-ethanolic extract of unripe fruits of Aegle marmelos. Results of this study concludes that the presence of gallic acid and quercetine that might be responsible for its antidiarrhoeal, antibacterial, astringent and anti-inflammatory activity in extract.
\end{abstract}

Keywords: Gallic acid, Aegle marmelos, HPTLC, biomarkers, quercetin

\section{Introduction}

Aegle marmelos is an important medicinal plant with wide ethno-medicinal applications in traditional and folk medicinal systems. Antidiarrheal activity is one of the major medicinal properties of $A$. marmelos which have been extensively used to control chronic diarrhea and dysentery ${ }^{[1,2]}$. Recently, several in vitro and in vivo studies have been conducted to confirm the antidiarrheal property of $A$. marmelos. It has also been traditionally used for the treatment of various infectious diseases. Many workers reported antibacterial activity of the leaves, fruits and barks of Aegle marmelos ${ }^{[3,4,5]}$.

Decoction of unripe fruit is astringent, useful in diarrhea and chronic dysentery. Aegle marmelos fruit is astringent, laxative, digestive, stomachic, brain and heart tonic as reported by several researchers ${ }^{[6]}$. The ripe fruit promotes digestion and is helpful in treating inflammation of rectum. Methanol and aqueous extract of Beal fruit have shown strong activity against multi drug resistant $S$. typhimurium. The effectiveness of Aegle marmelos fruit in diarrhea and dysentery has resulted in its entry into the British pharmacopoeia ${ }^{[7]}$.

A. marmelos plant has been blessed with seven major phytochemicals such as alkaloids, cardiac glycosides, terpenoids, saponins, tannins, flavonoids and steroids which are biologically active and have been the major source in curing different diseases. Extensive investigations have been carried out on different parts of A. marmelos ${ }^{[8]}$. Anti-diarrhoeal and anti-dysenteric of medicinal plants were found to be due to the presence of tannins, alkaloids, saponins, flavonoids, steroids and terpenoids ${ }^{[9]}$. In the past, many research has been done on this phytochemical aspects and the studies have shown that the fruit pulp of A. marmelos contains bio active substance like carotenoids, tannins, flavonoids, terpenoids, alkaloids, pectins, reducing sugar, saponins, carbonyls, phlobatanins and steroids ${ }^{[10,11,12]}$.

However, very scanty information is available on quantification of phytochemical evaluation of extract of Beal fruit. Hence, unripe fruits extract of Aegle marmelos was selected to undertake quantitative phytochemical studies. In the present study, quantitative phytochemical analysis (HPTLC) of unripe fruits extract of Aegle marmelos was carried out to know the active bioactive compounds responsible for anti-diarrhoeal and antibacterial activity present in 
this plant. Gallic acid, rutin and quercetin which are important active constituents of medicinal plants selected in the present study were estimated by High performance thin layer chromatography (HPTLC) method.

\section{Materials and Methods \\ Preparation of Cold Extract}

The unripe fruits of Aegle marmelos were collected and shade dried and processed to get fine powder with the help of pulverizing machine. Freshly prepared powder (25 g) was immersed in hydro-ethanolic solution (40\% distilled water + $60 \%$ ethanol) in a flask stoppered tightly with cotton plug and kept on orbital shaker at room temperature for 48 hours at 150 rpm. The contents of the flask were filter through Whatman No. 1 filter paper. Final filtrate was evaporated and per cent extractability was determined. The extract was store in airtight screw cap vials and kept in the desiccator until further use in this study.

\section{High Performance Thin Layer Chromatography [HPLC] Methodology}

The present study was directed towards the quantitative estimation of biomarkers gallic acid, Rutin and Quercetin in hydro-ethanolic extracts of unripe fruits of Aegle marmelos.

\section{Instrumentation}

Analysis was performed on a CAMAG HPTLC system equipped with a sample applicator Linomat V, $100 \mathrm{ml}$ syringe (Hamilton, Bonaduz, Switzerland), twin trough development chamber $(20 \mathrm{~cm} \times 10 \mathrm{~cm})$ size, TLC Scanner III linked to WinCats software (CAMAG), $0.2 \mathrm{~mm}$ thickness pre-coated with silica gel 60 F254 (Merck) were used in this study.

\section{Reagents and Chemicals}

Analytical grade Toluene, Ethyl acetate, Methanol, Formic acid, was obtained. Gallic acid, Quercetin and Rutin were obtained from the Natural Remedies Ltd, Bangalore. Precoated TLC aluminium sheets silica gel 60F254 (10 x10 $\mathrm{cm}, 0.2 \mathrm{~mm}$ thick) were obtained from E. MERCK KGaA.

\section{Procedure}

Analysis was performed on $20 \mathrm{~cm} \times 10 \mathrm{~cm}$ HPTLC silica gel G60 F254 plates with fluorescent indicator. Before starting the analysis, HPTLC plates were cleaned by predevelopment with methanol by ascending method. HPTLC plate was immersed in a CAMAG glass chamber $(20 \mathrm{~cm} \times 10 \mathrm{~cm})$, containing $30 \mathrm{ml}$ methanol (HPLC grade) as solvent system. The chamber was covered with glass lid and left till development of the plate to the top with methanol. After complete development, the plate was removed from TLC glass chamber and dried in an oven. Three spots of $10 \mu \mathrm{l}$ were applied (in the form of band) of standard preparation along with three spots of $10 \mu \mathrm{l}$ of sample preparation as the bands on the same plate by means of a CAMAG Linomat 5 (automated spray-on applicator equipped with a $100 \mu \mathrm{l}$ syringe and operated with the settings band length $6 \mathrm{~mm}$, distance between band $15 \mathrm{~mm}$, distance from the plate side edge $15 \mathrm{~mm}$ and distance from the bottom of the plate 15 $\mathrm{mm})$.

\section{TLC Development and Scanning (Chromatographic Conditions)}

Samples of extracts and standard Gallic acid and Rutin were spotted on a Precoated TLC aluminium sheets silica gel 60 F254 (10x10cm, $0.2 \mathrm{~mm}$ thickness) as $8 \mathrm{~mm}$ wide band width by using automatic TLC applicator Linomat V,10 mm from the bottom. The Mobile phase used was Toulene: Ethyl Acetate: Formic Acid: Methanol (3:3:0.3:0.2) for Gallic acid, Quercetin and Rutin. The plates were kept for saturation in twin trough chamber for $15 \mathrm{~min}$. After development the plates were dried in oven and scanned at 200, 250, 300, 350, 400, $450 \mathrm{~nm}$ for Gallic acid, Quercetin and Rutin by using CAMAG Scanner III.

\section{Calibration Curve for Standards}

The standard solutions were applied on TLC plate and further it was developed and scanned as per the chromatographic conditions mentioned above. The peak areas were recorded. Calibration curve of Gallic acid, Quercetin and Rutin was prepared by plotting peak area against concentration of standard applied.

\section{Results and Discussion}

In the present analysis, the given samples were measured at wavelength 200 to $450 \mathrm{~nm}$ with reference to Gallic acid, Rutin as Rutin trihydrate and Quercetin as Quercetin dihydrate as standards in mobile phase Toulene: Ethyl Acetate: Formic Acid: Methanol (3:3:0.3:0.2).

The HPTLC profile for hydro-ethanolic unripe fruits extract of Aegle marmelos is presented in Table 1. The $R f$ value of standard gallic acid scanned at 200, 250, 300, 350, 400 and $450 \mathrm{~nm}$ were found to be $0.19,0.18,0.16,0.19,0.20$ and 0.20 , respectively. The average $R f$ value of gallic acid was 0.18 , showed peak of gallic acid. In gallic acid standard peak number 3 at wavelength $250 \mathrm{~nm}, 350 \mathrm{~nm}, 400 \mathrm{~nm}$ and $450 \mathrm{~nm}$ found in average $83.05 \%$ area i.e. more pure form of gallic acid at Rf 0.18 and at wavelength 200 and 300nm found $\mathrm{Rf}$ 0.18 shows $67.21 \%$ and $88.23 \%$ area in peak number 4 and 2 , respectively. It confirmed that gallic acid was present in the sample.

The standard rutin was scanned at 200, 250, 300, 350, 400 and $450 \mathrm{~nm}$, however, no peak was seen at wavelength 200 to $450 \mathrm{~nm}$. It confirmed that rutin was absent in the sample.

The $R f$ value of standard quercetin scanned at 200, 250, 300, 350,400 and $450 \mathrm{~nm}$ were found to be $0.32,0.30,0.28,0.29$, 0.29 and 0.30 , respectively. The average $R f$ value of quercetin was 0.29 , showed peak of quercetin. In Quercetin dihydrate standard peak no. 2 at 250 to $450 \mathrm{~nm}$ and peak no. 3 at $200 \mathrm{~nm}$ found highest purity i.e. in average $85.23 \%$ area and Rf 0.29 . It found that sample contain Quercetin dihydrate.

In track 5 of Aegle marmelos at wavelength 200 to $350 \mathrm{~nm}$ compound gallic acid was found at Rf 0.21 i.e. very nearer to standard of gallic acid peak, showed presence of gallic acid. No peak for gallic acid was evident at wavelength $450 \mathrm{~nm}$. At wavelength 200 to $350 \mathrm{~nm}$ compound quercetin was found with $\mathrm{Rf} 0.33$ i.e. $R f$ value was coinciding with standard $R f$ value of quercetin, showed presence of quercetin. No peak was seen in track 5 and 6 of standard Rutin. It confirmed the absence of rutin in the sample.

The $R f$ values for gallic acid and quercetin in sample and reference standard were found comparable. These observations indicated the presence of gallic acid and quercetin in hydro-ethanolic unripe fruits extract of Aegle marmelos (Table 1). Some workers also characterized the various phenolics in the fruit extract of Aegle marmelos as chlorogenic acid, gallic acid, ellagic acid and quercetin through LC-MS and HPLC studies ${ }^{[13]}$.

The HPTLC chromatograms are useful in identification of biomarkers in various herbal formulations by comparing the fingerprints with standards. Gallic acid; rutin and quercetin 
are important active constituents of many herbal plants. Rutin and quercetin are polyphenol flavonoids found in many herbal plants. They mainly include flavonoïds (e.g. quercetin), glycosides (e.g. rutin) and simple phenols (e.g. gallic acid). Flavonoïds is a group of polyphenol compounds, which are widely distributed through the plant tissues. Flavonoïds occur in plant tissues in a free state, (Quercetin: 5, 7, 3', 4'tetrahydroxy flavonol), or in glycosides (Rutin: 5, 7, 3, 4, tetrahydroxy flavonol-3-rhamnoglucoside). Quercetin and rutin are the most common flavonoïds found in plant tissues. [14] Gallic acid is a type of simple phenol compounds $(3,4,5-$ trihydroxybenzoates) found commonly in plant tissues. It possesses an astringent activity. Tannins and flavonoids in general have been reported to have antidiarrhoeal activity through inhibition of intestinal motility, antimicrobial action and antisecretory effects ${ }^{[11]}$. Therefore, in the present quantitative estimation, the gallic acid is well represented in chromatogram.

Many workers reported presence of carbohydrates, glycosides, amino acids, proteins, tannins, flavanoids, phytosterols in extract of dried unripe fruit pulp of $A$. marmelos. ${ }^{[10,11]}$. Some workers reported the the presence of chemicals like Alkaloids, Cardiac glycosides, Terpenoids,
Saponins, Tannis, Flavonoids and Steroids in crude ethanolic extracts of Bael fruit which was effective against the tested organisms Staphylococcus aureus, Bacillus subtilis, Escherichia coli, Pseudomonas aeruginosa and Bacillus subtilis due to the presence of these bioactive constituents in the extract ${ }^{[9]}$. Many researchers reported alkaloids, $\mathrm{N}$-2-[4(3',3'-dimethylallyloxy) phenyl] ethyl cinnamide, $\mathrm{N}$-2hydroxy-2-[4-(3',3'- dimethylallyloxy) phenyl] ethyl cinnamide or marmeline, $N$-4- methoxystyryl cinnamide and $\mathrm{N}$-2-hydroxy-2-(4-hydroxyphenyl) ethyl cinnamide and aegeline from fruits of $A$. marmelos ${ }^{[15,16]}$.

The present quantitative analysis of three biomarkers by the HPTLC methods indicated that the gallic acid was the most abundant biomarker present in the extract, as it is was well represented in chromatogram. HPTLC study of extract showed presence of gallic acid and quercetine that might be responsible for its anti-diarrhoeal, antibacterial, astringent and anti-inflammatory activity in extract. Thus, the results of the present study support the anti-diarrhoeal, antibacterial, astringent and anti-inflammatory activity in extract of unripe fruits of Aegle marmelos. In the present investigation, HPLTC method was found effective for the separation of rutin, quercetin and gallic acid.

Table 1: HPTLC profile for standard biomarkers and hydroethanolic extract of unripe fruits of Aegle marmelos

\begin{tabular}{|c|c|c|c|c|c|c|c|c|c|}
\hline \multirow{2}{*}{$\begin{array}{c}\text { S. } \\
\text { No. }\end{array}$} & \multirow{2}{*}{ Name of sample } & \multicolumn{6}{|c|}{ Wave length (in nm) } & \multirow{2}{*}{ Observation } & \multirow{2}{*}{ Inference } \\
\hline & & 200 & 250 & 300 & 350 & 400 & 450 & & \\
\hline 1 & Gallic acid std & $\begin{array}{c}\mathrm{Rf}-0.19 \\
\text { \% Area }-67.21 \\
\text { Peak no.- } 4\end{array}$ & \begin{tabular}{|c|}
$\mathrm{Rf}-0.18$ \\
$\%$ Area -78.09 \\
Peak no.-3
\end{tabular} & \begin{tabular}{|c|} 
Rf -0.16 \\
$\%$ Area- 88.23 \\
Peak no.-2
\end{tabular} & \begin{tabular}{|c|}
$\mathrm{Rf}-0.19$ \\
$\%$ Area -82.63 \\
Peak no.- 3
\end{tabular} & $\begin{array}{c}\text { Rf }-0.20 \\
\text { \% Area }-86.11 \\
\text { Peak no.-3 }\end{array}$ & \begin{tabular}{|c|} 
Rf -0.20 \\
\% Area -85.37 \\
Peak no.-3
\end{tabular} & $\begin{array}{c}\text { At Rf } 0.18 \text { shows } \\
\text { peak of Gallic } \\
\text { acid }\end{array}$ & Gallic acid is present \\
\hline 2 & $\begin{array}{l}\text { Rutin trihydrate } \\
\text { std }\end{array}$ & & & & & & & No peak & No peak \\
\hline 3 & $\begin{array}{c}\text { Quercetin } \\
\text { dihydrate std }\end{array}$ & $\begin{array}{c}\mathrm{Rf}-0.32 \\
\% \text { Area-72.35 } \\
\text { Peak no.- } 3\end{array}$ & $\begin{array}{c}\mathrm{Rf}-0.30 \\
\% \text { Area }-78.35 \\
\text { Peak no.-2 }\end{array}$ & $\begin{array}{c}\text { Rf }-0.28 \\
\text { \% Area }-83.24 \\
\text { Peak no.-2 }\end{array}$ & $\begin{array}{c}\text { Rf }-0.29 \\
\text { \% Area-90.02 } \\
\text { Peak no.-2 }\end{array}$ & $\begin{array}{c}\text { Rf }-0.29 \\
\text { \% Area }-18.7 \\
\text { Peak no.-2 }\end{array}$ & \begin{tabular}{|c|} 
Rf -0.30 \\
\% Area 94.54 \\
Peak no.-2
\end{tabular} & \begin{tabular}{|} 
At Rf 0.29 shows \\
peak of \\
Quercetin \\
dihydrate
\end{tabular} & $\begin{array}{l}\text { Quercetin dehydrate } \\
\text { present }\end{array}$ \\
\hline 4 & $\begin{array}{c}\text { Sample - Aegle } \\
\text { marmelos } \\
\text { Track } 5\end{array}$ & $\begin{array}{l}\text { Rf- } 0.20 \\
\text { Rf- } 0.38\end{array}$ & $\begin{array}{l}\text { Rf- } 0.21 \\
\text { Rf- } 0.33\end{array}$ & $\begin{array}{l}\text { Rf- } 0.21 \\
\text { Rf- } 0.29\end{array}$ & $\begin{array}{l}\text { Rf- } 0.21 \\
\text { Rf- } 0.30\end{array}$ & & No peak & $\begin{array}{l}\text { No peak at } \\
450 \mathrm{~nm}\end{array}$ & $\begin{array}{c}\text { Gallic acid and } \\
\text { Quercetin may be } \\
\text { present }\end{array}$ \\
\hline & Track 6 & $\begin{array}{l}\text { Rf- } 0.19 \\
\text { Rf- } 0.31\end{array}$ & $\begin{array}{l}\text { Rf- } 0.21 \\
\text { Rf- } 0.34\end{array}$ & $\begin{array}{l}\text { Rf- } 0.22 \\
\text { Rf- } 0.29\end{array}$ & $\begin{array}{l}\text { Rf- } 0.21 \\
\text { Rf- } 0.32\end{array}$ & Rf- 0.23 & No peak & $\begin{array}{c}\text { No peak at } 450 \\
\mathrm{~nm}\end{array}$ & $\begin{array}{c}\text { Gallic acid and } \\
\text { Quercetin may present }\end{array}$ \\
\hline
\end{tabular}

\section{References}

1. Patel P, Asdaq SMB. Immunomodulatory activity of methanolic fruit extract of Aegle marmelos in experimental animals. Saudi Pharm. J. 2012; 18:161-165.

2. Rao HJG, Lakshmi P. Evaluation of anti-diarrhoeal activity of extract from leaves of Aegle marmelos. Journal of applied Pharmaceutical Science. 2012; 2(02):75-78.

3. Poonkothai M, Saravanan M. Antibacterial activity of Aegle marmelos against leaf, bark and fruit extracts. Anc Life Science. 2008; 27(3):15-18.

4. Joshi PV, Patil RH, Maheshwari VI. In vitro antidiarrhoeal activity and toxicity profile of Aegle marmelos Correa ex Roxb. Dired fruit pulp'. Natural Product Radiance. 2009; 8(15):498-502.

5. Maheshwari VL, Joshi PV, Patil RH. In vitro anti diarrhoeal activity and toxicity profile of Aegle marmelos Correa ex. Roxb. Dried fruit pulp. Natural Product Radiance. 2009; 8(5):498-502.

6. Gupta Kunal, Karale Sanjiv, Warad Vijaanand. Antidiarrhoeal activity of polyherbal formulations in various animals model of diarrhea, International Research Journal of Pharmacy. 2012; 3(8):289-294.

7. Chopra R. Indigenous drugs of India Calcutta. Academic Publishers, 1982.
8. Dhankhar Sandeep, Ruhil S, Balhara M, Dhankhar Seema, Chhillar AK. Aegle marmelos (Linn.) Correa: A potential source of Phytomedicine. Journal of Medicinal Plants Research. 2011; 5(9):1497-1507.

9. Venkatesan D, Karrunakarn CM, Selva Kumar S, Palani Swamy PT. Identification of Phytochemical Constituents of Aegle marmelos Responsible for Antimicrobial Activity against Selected Pathogenic Organisms. Ethnobotanical Leaflets. 2009; 13:1362-1372.

10. Brijesh SP, Daswani P, Tetali N, Anita, Birdi T. Studies on the antidiarrhoeal activity of Aegle marmelos unripe fruit: Validating its traditional usage, BMC Complement Altern Med. 2009; 9:47-58.

11. Rajan S, Gokila M, Jencyu P, Brindha P, Sujatha RK. Antioxidant and Phytochemical properties of Aegle Marmelos Fruit pulp. International journal of current pharmaceuticals Research. 2011; 3(2):65-70.

12. Sharma GN, Dubey SK, Sati N, Sanadya J. Phytochemical Screening and Estimation of Total Phenolic Content in Aegle marmelos Seeds. International Journals of Pharmaceutical and Clinical Research. 2011; 3(2):27-29.

13. Dhan ML, Dhar MM, Dhawan BN, Mehrotra BN, Ray C. Screening of Indian plants for biological activity: I. Indian Journal of Experimental Biology. 2000; 6(4):232247. 
14. Sajeeth CI, Manna PK, Manavalan R, Jolly CI. Quantitative estimation of Gallic Acid, Rutin and Quercetin in certain herbal plants by HPTLC method. Pelagia Research Library Der Chemica Sinica. 2010; 1(2):80-85.

15. Lmbole VB, Murti K, Kumar U, Bhatt SP, Gajera V. Phyto pharmacological Properties of Aegle marmelos as a Potential Medicinal Tree: An Overview. International Journal of Pharmaceutical Science Review and Research. 2010; 5(2):55-59.

16. Baliga MS, Bhat HP, Joseph N, Fazal F. Phytochemistry and medicinal uses of the Bael fruit (Aegle marmelos Correa): A concise review, Food Research International. 2012; 44:1768-1775. 